\title{
JUROS ALTOS, FONTES DE FINANCIAMENTO E ESTRUTURA DE CAPITAL: O ENDIVIDAMENTO DE EMPRESAS BRASILEIRAS NO PERÍODO 1997-2006
}

\section{HIGH INTEREST RATES, CAPITAL SOURCES AND CAPITAL STRUCTURE: THE DEBT OF BRAZILIAN COMPANIES IN THE PERIOD 1997-2006}

\author{
Mauricio Ribeiro do Valle ${ }^{a}$;atiana Albanez ${ }^{b}$ \\ ${ }^{a}$ Livre docente em Controladoria e Contabilidad pela FEA-RP/USP \\ Docente da Faculdade de Economia,Administração e Contabilidade de Ribeirão Preto da Universidade de São Paulo FEA-RP/USP \\ E-mail:marvalle@usp.br \\ ${ }^{b}$ Doutora em Ciencias Contábeis pela FEA/USP \\ Docente da FIPECAFI e FIA, Consultora do Centro de Estudos de Mercado de Capitais (Cemec/IBMEC), \\ E-mail: tatiana.albanez@gmail.com
}

\section{Resumo}

Estudos ressaltaram a necessidade de se incorporar à análise das estruturas de capital das empresas fatores que não apenas as suas próprias características. Rajan e Zingales (1995) e Booth et al. (2001) indicaram a importância de incorporar fatores institucionais e Faulkender e Petersen (2006) apontaram a necessidade de se incorporar não apenas fatores relacionados à característica da firma (o lado da demanda), mas também fatores relacionados à fonte dos recursos (o lado da oferta). O presente trabalho analisa a influência do acesso a (1) fontes de recursos com taxas de juros diferenciadas (subsidiadas) e a (2) recursos em moeda estrangeira, que representam fatores institucionais e/ou o lado da oferta de recursos, no endividamento de empresas brasileiras nos anos 1997 a 2006, período em que várias pré condições macroeconômicas para o desenvolvimento das atividades empresariais no Brasil estiveram longe do minimamente razoável, permitindo analisar o que fizeram as empresas brasileiras com suas estruturas de capital em um ambiente de altas taxas de juros. Para tanto, foram utilizadas variáveis clássicas da literatura de estrutura de capital e variáveis representativas de fatores institucionais num painel de dados referente a empresas brasileiras de setores industriais, cujas ações foram negociadas na BM\&FBovespa no período 1997-2006. Os resultados demonstraram que: i) as fontes diferenciadas de recursos e as linhas em moeda estrangeira tiveram participação significativa no nível de endividamento de empresas brasileiras; e ii) a inclusão do acesso a estas fontes, juntamente com variáveis comumente utilizadas (tamanho, rentabilidade etc.) nos modelos de análise do nível de endividamento, contribuiu para o entendimento da estrutura de capital de empresas brasileiras.

Palavras-chave: Estrutura de capital; Fontes de financiamento; Taxas de juros diferenciadas; Teoria de trade-off; Teoria de pecking order

\begin{abstract}
Several studies have emphasized the necessity of incorporating factors unrelated to the firm characteristics into their capital structure analysis. Rajan and Zingalas (1995) and Booth et al. (2001) argued for the importance of institutional factors which have remained unexplored and Faulkender and Petersen (2006) have looked at the role of access to the public debt market in the determination of the leverage level. This paper evaluates the impact of (1) specific sources of capital with differentiated (subsidized) interest rates and (2) resources denominated in foreign currencies in the leverage of the Brazilian firms in the years 1997 to 2006, period in that several macroeconomic conditions for the development of the business activities in Brazil were far away from the reasonable, allowing to analyze what did the Brazilian companies with their capital structures in an environment of high interest rates. In order to do so we used classic variables of capital structure literature and variables representing institutional factors in a panel data regarding Brazilian firms in industrial sectors traded in BM\&FBovespa in the period 1997-2006. The results showed that: $i)$ the specific sources of capital and foreign currency lines have had a significant impact on the level of indebtedness of Brazilian firms; and ii) including access to these specific sources together with classic variables in the models for determining levels of indebtedness contributed to the understanding of the capital structure of the Brazilian firms.
\end{abstract}

Keywords: Capital structure; Capital sources; Differentiated interest rates; Trade-off theory; Pecking order theory. 


\section{INTRODUÇÃO}

Há um pouco mais de 50 anos, Modigliani e Miller (1958) plantavam a semente da moderna teoria de estrutura de capital. Dada sua simplicidade metodológica, seu desenvolvimento lógico e sua forte argumentação, o que parecia uma contribuição definitiva para o entendimento das estruturas de capital de empresas tornou-se raiz de acirrada discussão teórica e empírica, estampou o desconhecimento existente sobre o assunto e lançou dúvidas sobre os verdadeiros determinantes das estruturas de capital das empresas. No primeiro parágrafo de seu clássico The Capital Structure Puzzle, Myers (1984, p. 575) pergunta: "How do firms choose their capital structures?" e responde: "We don't know".

De Modigliani e Miller (1958) para cá, passando por Myers e outros importantes estudiosos, são anos de vasta produção acadêmica, de questionamentos vários, de novos posicionamentos teóricos e de tentativas de comprovações empíricas a favor ou contra suas principais postulações. Provavelmente se formulada hoje, a resposta à pergunta de Myers seria a mesma: "nós não sabemos". E nós, o que sabemos da estrutura de capital das nossas empresas? Como as nossas empresas escolhem suas estruturas de capital?

Trabalhando-se numa linha essencialmente empírica, pergunta-se: é possível aplicar o arcabouço teórico e metodológico desenvolvido para se estudar empresas de países desenvolvidos à realidade brasileira? Trabalhos que analisaram conjuntamente diferentes países, a partir do que foi desenvolvido para empresas de um único país (geralmente desenvolvido) indicam que sim, mas com alguns pontos a serem considerados. Rajan e Zingales (1995), em trabalho que procuraram verificar se os fatores comumente associados às estruturas de capital das empresas americanas também se confirmavam importantes para outros países, estudaram empresas dos países mais industrializados do mundo e concluíram que os fatores que influenciam a alavancagem de empresas americanas parecem influenciar também a alavancagem destes países, sendo que as diferenças existentes não são explicadas facilmente apenas por fatores institucionais.

Para justificar a aplicação destes estudos à realidade brasileira, merece destaque o trabalho de Booth et al. (2001). A partir do estudo com empresas de dez países em desenvolvimento, os autores concluíram que o nível de endividamento de empresas nestes países parece ser afetado da mesma maneira e pelos mesmos tipos de variáveis que são significativas em países desenvolvidos. Terra (2007), estudando empresas latino-americanas, chegou a conclusões parecidas.

Estas três referências, em diferentes épocas e contextos, permitem a resposta "sim" à pergunta formulada. Mas, por outro lado, vários autores também enfatizaram a insuficiência do que se estuda para se tentar explicar os aspectos relacionados às estruturas de capital. Para que esta Introdução não se estenda demasiadamente, restringimo-nos ao que apontaram os já mencionados trabalhos.

Rajan e Zingales (1995, p. 1458) afirmaram: "é necessário fortalecer a relação entre modelos teóricos e especificações empíricas. [...] Por outro lado, um entendimento mais profundo dos efeitos de diferenças institucionais é necessário." ${ }^{\prime \prime}$ Booth et al. (2001, p. 118) destacaram: "embora algumas das variáveis independentes tenham o sinal esperado, seu impacto global é baixo e os sinais às vezes variam entre os países. Esta observação pode [...] também insinuar que diferenças institucionais significativas afetam a importância das variáveis

1 "It is necessary to strengthen the relationship between theoretical models and empirical specifications of those models. [...] On the other hand, a deeper understanding of the effects of institutional differences is necessary." (RAJAN E ZINGALES, 1995, p. 1458). 
independentes."2 Terra (2007) também destacou a insuficiência dos resultados encontrados, mas sugeriu que o caminho para se aprofundar o estudo nesta área deve enfatizar as características das empresas e não as questões institucionais.

Antes de avançarmos, merece ser mencionado ainda o trabalho de Faulkender e Petersen (2006), segundo o qual a literatura empírica deveria concentrar os seus estudos não apenas sobre as características específicas da firma. Para os autores, "é importante incluir não apenas os determinantes da alavancagem preferida (o lado da demanda), mas também as variáveis que medem as restrições na habilidade de uma empresa em aumentar sua alavancagem (o lado da oferta)"3 (Faulkender e Petersen, 2006, p. 45-46). Para focar este ponto, os autores analisaram a relação entre a fonte de capital (private versus public debt market) e a estrutura de capital e confirmaram a importância da fonte de recursos no nível de endividamento das firmas.

Desta discussão, desenvolveu-se a idéia central do presente artigo. Entende-se que, além de se considerar as características das empresas, amplamente estudadas na literatura, é necessário avançar no sentido de compreender quais são as questões institucionais, as características do momento econômico ou os aspectos do lado da oferta de recursos, conforme se depreendeu de sugestões deixadas por autores como Rajan e Zingales (1995), Booth et al. (2001) e Faulkender e Petersen (2006), e incorporá-las aos estudos de estrutura de capital das empresas brasileiras.

Dessa forma, o presente trabalho analisa a estrutura de capital de empresas brasileiras no período 1997-2006, período em que várias pré-condições macroeconômicas para o desenvolvimento das atividades empresariais estiveram longe do minimamente razoável. No que diz respeito às decisões de estrutura de capital, vale lembrar que as taxas de juros nacionais foram sempre bastante superiores às taxas internacionais. As altas taxas de juros praticamente se tornaram uma instituição brasileira que pareceu eterna durante muito tempo.

Neste contexto, surge a seguinte questão de pesquisa: em um ambiente de altas taxas de juros, o que fizeram as empresas brasileiras com suas estruturas de capital? Em contrapartida aos altos juros, o país tinha desenvolvido mecanismos próprios de financiamento de suas empresas, com destaque para duas fortes instituições nacionais: o Banco Nacional de Desenvolvimento Econômico e Social - BNDES e o Crédito Rural, ambos com taxas de juros diferenciadas (subsidiadas), abaixo das taxas praticadas livremente entre os agentes econômicos.

Aliando-se os argumentos de autores que indicaram a importância de fatores institucionais ainda não explorados (Rajan e Zingales, 1995; Booth et al., 2001) com os de Faulkender e Petersen (2006), que examinaram o impacto do acesso que empresas têm a diferentes fontes de recursos, ao fato de a presente análise ocorrer em um período com características macroeconômicas e institucionais tão particulares, desenvolve-se a hipótese central do artigo: o acesso a fontes de recursos diferenciadas, como BNDES e Crédito Rural, e recursos em moeda estrangeira, foi crucial para a determinação da estrutura de capital de empresas brasileiras. Sabendo-se da existência de fontes de recursos privilegiados, procura-se, como principal objetivo, analisar a estrutura de capital de empresas brasileiras incorporando o elemento "acesso a fontes diferenciadas e a linhas em moeda estrangeira" ao estudo dos determinantes dos níveis de endividamento destas empresas no período 1997-2006.

2 "Although some of the independent variables have the expected sign, their overall impact is low and the signs sometimes vary across countries. This latter observation could [...] also imply significant institutional differences that affect the importance of the independent variables." (ВOOTH et al., 2001, p. 118).

3 "It is important to include not only the determinants of its preferred leverage (the demand side) but also the variables that measure the constraints on a firm's ability to increase its leverage (the supply side)." (FAULKENDER E PETERSEN, 2006, p. 45-46). 


\section{REFERENCIAL TEÓRICO}

A revisão que segue está organizada a partir das variáveis que serão incluídas no estudo, que foram as que melhor explicaram a estrutura de capital de empresas brasileiras no período 1997-2006, dentre diversas variáveis estudadas nas versões preliminares deste trabalho ${ }^{4}$. Não se pretende uma revisão ampla de todos os incontáveis trabalhos empíricos nem uma revisão dos trabalhos pioneiros ou dos trabalhos mais recentes. Foram priorizados textos que bem elaboraram a justificação teórica de cada variável.

\section{a) Tamanho da empresa}

As hipóteses teóricas para justificar uma relação existente entre tamanho da firma e alavancagem são várias. Provavelmente, a mais mencionada é a relacionada às questões de agência.

Stohs e Mauer (1996, p. 283), a partir de discussões teóricas de Myers (1977), Smith Jr. e Warner (1979b) e Barnea, Haugen e Senbet (1980, 1985), argumentaram: “empresas menores que, provavelmente, enfrentam mais severos conflitos de agência que empresas maiores e bem estabelecidas, podem usar dívida de curto prazo para amenizar estes conflitos." ${ }^{5} \mathrm{Tal}$ argumentação levou estes autores a investigarem a hipótese empírica de que a maturidade da dívida varia diretamente com o tamanho da firma. Ozkan (2002), além de ter analisado questões de agência (firmas menores têm maiores custos de agência), fundamentando-se em Smith Jr. e Warner (1979b) e Barnea, Haugen e Senbet (1980), considerou os seguintes fatores: i) as firmas maiores têm acesso mais fácil ao mercado de capitais, argumento trabalhado inicialmente por Titman e Wessels (1988); e ii) as firmas menores possuem uma proporção menor de ativos que podem ser dados como garantia em relação às oportunidades de investimentos (Ozkan, 2002).

Adicionalmente, Titman e Wessels (1988) investigaram a hipótese de que, por serem mais diversificadas, as empresas maiores estão menos propensas à falência e, por isso, podem ser mais alavancadas. Ainda, mencionaram que os custos (fixos) para emissão de dívida ou ações são proporcionalmente maiores para empresas pequenas, o que as leva a preferir dívidas bancárias de curto prazo. Guedes e Opler (1996) também se fundamentaram indiretamente em questões relacionadas à falência. Para os autores, a constatação de que empresas maiores emitem dívidas de prazos mais curtos é consistente com a hipótese de liquidity risk ${ }^{6}$, elaborada por Diamond (1991), devido ao fato de que grandes empresas são menos prováveis de sofrer inadimplência.

Já Rajan e Zingales (1995) destacaram o risco de falência e assimetria de informações para justificar a relação entre tamanho e alavancagem. Para estes autores, esta relação é ambígua. Por um lado, como firmas maiores tendem a ser mais diversificadas - o que implicaria em menor probabilidade de falência - o tamanho deveria apresentar um impacto positivo na oferta de dívida. Por outro lado, argumentaram que em empresas maiores a assimetria de informações entre insiders e o mercado de capitais é menor, o que faz com que estas empresas (as maiores) sejam mais capazes de emitir títulos mais sensíveis à informação, como são as

4 Ainda foram testados os seguintes atributos: longevidade dos ativos (ou asset maturity); economia fiscal não advinda de dívida; qualidade da firma (firm quality ou signalling hiphotesis); rating; e impostos. Em alguns casos, testou-se mais de uma variável representativa de cada atributo.

5 "Smaller firms who likely face more severe agency conflicts than large, well-established firms may use shorter-term debt to alleviate these conflicts." (STOHS E MAUER, 1996, p. 283).

6 Devido à existência do risco de liquidez, o modelo de Diamond (1991) prediz que a maturidade da dívida é uma função das avaliações de risco. 
ações comparativamente aos títulos de dívida. Tal argumentação leva a se esperar que empresas maiores tenham menos dívida.

\section{b) Tangibilidade dos ativos}

O principal suporte para justificar uma relação entre ativos que podem ser dados em garantia e alavancagem está baseado na teoria de agência. Smith Jr. e Warner (1979a) investigaram a hipótese de que dívida com garantia (secured debt) é uma forma de impedir que os tomadores promovam, após emitirem a dívida, substituição de ativos. De acordo com Harris e Raviv (1991), a substituição de ativos constitui um dos problemas de agência, configurandose no incentivo que os executivos podem ter para substituir os ativos atuais por ativos de maior risco após a emissão da dívida, com o intuito de transferir valor dos detentores de títulos de dívida para os acionistas (sobre asset substitution, ver Harris e Raviv, 1991, p. 301). Uma vez que os credores reconhecem o risco de substituição de ativos, exigirão taxas de juros que o compensem. Por sua vez, a possibilidade de emissão de uma dívida garantida por penhor de ativos diminuirá a flexibilidade que o tomador terá para substituir projetos e para emitir dívidas adicionais sobre aqueles ativos, o que, em conseqüência, diminuirá a taxa exigida pelos credores.

Titman e Wessels (1988), fundamentando-se em Myers \& Majluf (1984), afirmaram que quando os executivos têm melhores informações que os acionistas externos, emitir dívidas garantidas por propriedades pode evitar os custos (de agência) associados a tal emissão. Por isto, firmas com ativos que podem ser dados em garantia provavelmente emitem mais dívidas para aproveitarem esta vantagem. De forma semelhante, para Rajan e Zingales (1995), como os ativos tangíveis podem servir de garantia para operações financeiras, diminuindo o custo de agência da dívida para os credores, e também como possuem mais valor numa liquidação, espera-se que, quanto maior a proporção de ativos tangíveis no ativo total da firma, maior a disposição dos credores em financiar e, por conseqüência, maior deveria ser a alavancagem.

Demirgüç-Kunt e Maksimovic (1999), fundamentando-se em Myers (1977), afirmaram que as empresas cujo principal ativo é o valor presente das oportunidades de crescimento não conseguem tomar emprestado de forma ótima. Mas aquelas com uma grande quantidade de ativos fixos não enfrentam esse problema, uma vez que por servirem como garantia tais ativos facilitam a captação. Ao explicar a relação esperada entre tamanho e dívidas de longo prazo, Ozkan (2002, p. 20) afirmou: "empresas menores geralmente são impedidas de acessar mercados de dívida de longo prazo devido à menor proporção de seus ativos que podem ser usados como garantia das oportunidades de investimento futuras."

\section{c) Expectativa ou oportunidades de crescimento}

A sustentação teórica para os autores que procuram relacionar a estrutura de capital às expectativas de crescimento (que geram ativos intangíveis) é feita em grande medida também a partir da discussão de agência.

Titman e Wessels (1988), fazendo referência ao risco de expropriação dos credores pelos acionistas quando estes controlam a firma e tendem a investir sub-otimamente, afirmaram que tal problema de agência é maior em indústrias com altas taxas de crescimento e deduziram que as expectativas de crescimento devem ser negativamente relacionadas aos níveis de dívida de longo prazo. Adicionalmente, os autores afirmaram que as "oportunidades de crescimento

7 "Smaller firms are generally precluded from accessing long-term debt markets because of the smaller proportion of their collateralizable assets to future investment opportunities." (OZKAN, 2002, p. 20). 
são ativos que adicionam valor a uma empresa, mas não podem ser utilizados como garantia e não geram lucro tributável"» (Titman e Wessels, 1988, p. 4), o que sugere uma relação negativa entre dívida e oportunidades de crescimento. Por outro lado, como a emissão de dívida de curto prazo pode servir como um redutor deste problema de agência (Myers, 1977), para os autores, se as firmas que têm uma taxa de crescimento maior substituírem as dívidas de longo prazo por dívidas de curto prazo, os índices de dívida de curto prazo devem ser positivamente correlacionados com as taxas de crescimento.

Rajan e Zingales (1995, p. 1451), fundamentando-se em Myers (1977), afirmaram que “companhias altamente alavancadas são mais prováveis de perder valiosas oportunidades de investimento. Assim, empresas que esperam alto crescimento futuro deveriam usar uma maior proporção de capital próprio." Para Stohs e Mauer (1996), firmas cujos ativos têm uma alta proporção de opções de crescimento usam dívidas de curto prazo. A argumentação para tal hipótese empírica também vem da discussão de agência encontrada em Myers (1977), para quem, segundo Stohs e Mauer (1996), o risco de sub-investimento pode ser controlado pela emissão de dívidas de curto prazo que venceriam antes das opções de investimentos serem exercidas. Barclay e Smith Jr. (1995) também haviam analisado esta mesma hipótese teórica.

\section{d) Rentabilidade}

Para o uso desta variável, Titman e Wessels (1988) apóiam-se na teoria de pecking order (Myers, 1984; Myers e Majluf, 1984), sob a qual as empresas usariam primeiramente lucros retidos, seguidos de dívida e, por fim, de emissão de novas ações. Assim, de acordo com Titman e Wessels (1988, p. 6): "a rentabilidade passada de uma empresa e, conseqüentemente, a quantia de lucro disponível para ser retido, deveria ser um importante determinante de sua estrutura de capital corrente."10 (Titman e Wessels, 1988, p. 6).

Por sua vez, para analisarem a relação existente entre lucratividade e alavancagem, Rajan e Zingales (1995) destacaram a ambigüidade existente na teoria. Da argumentação revisada pelos autores, destaca-se que, a partir de Myers e Majluf (1984), é de se esperar uma relação negativa entre estas variáveis, pois empresas mais rentáveis teriam mais recursos internos disponíveis para financiar seus investimentos, não precisando recorrer à utilização de recursos externos. Porém, pelo lado da oferta, os credores prefeririam financiar as firmas que têm fluxo de caixa corrente, argumento do qual se espera que decorra uma relação positiva entre lucratividade e alavancagem.

Strebulaev (2007) também mencionou as previsões contrárias na relação entre as variáveis lucratividade e alavancagem. Enquanto pela teoria de pecking order espera-se uma relação negativa entre as duas variáveis, pela teoria de trade-off espera-se uma relação positiva, uma vez que a maior lucratividade diminui os custos esperados de dificuldades financeiras e permite à firma aumentar os benefícios fiscais da utilização da dívida, o que levaria ao aumento da alavancagem.

\section{e) Risco}

8 "Growth opportunities are capital assets that add value to a firm but cannot be collateralized and do not generate current taxable income." (TITMAN E WESSELS, 1988, p. 4).

9 "Highly levered companies are more likely to pass up profitable investment opportunities. Therefore, firms expecting high future growth should use a greater amount of equity finance." (RAJAN E ZINGALES, 1995, p. 1451).

10 "The past profitability of a firm, and hence the amount of earnings available to be retained, should be an important determinant of its current capital structure." (TITMAN E WESSELS, 1988, p. 6). 
Stohs e Mauer (1996), fundamentando-se em Kane et al. (1985), formularam a hipótese de que o vencimento ou maturidade da dívida aumenta à medida que diminui a volatilidade do retorno da firma, pois ela não teria que "rebalancear" sua estrutura de capital tão freqüentemente de modo a abrandar os custos esperados de falência. Titman e Wessels (1988) também haviam analisado a hipótese de que o nível ótimo de dívida é uma função decrescente da volatilidade de seus lucros, mas não a confirmaram.

\section{f) Fontes diferenciadas de financiamento}

A inclusão de variáveis que representem fontes alternativas (e diferenciadas ou subsidiadas) de financiamento no estudo da estrutura de capital de empresas brasileiras justifica-se por dois motivos. Primeiramente, alguns trabalhos vêm apontando a necessidade de se incorporar aos estudos relacionados à estrutura de capital de empresas (1) elementos institucionais (Rajan e Zingales, 1995; Booth et al., 2001) e (2) elementos que representem a oferta dos recursos de capital (Faulkender e Petersen, 2006). Em segundo lugar, as características bastante particulares da economia brasileira no período estudado (juros altos) e de suas instituições (fontes diferenciadas de financiamento) confirmam a necessidade de se incorporar variáveis institucionais e/ou representativas da oferta de recursos.

Assim, à semelhança do trabalho de Faulkender e Petersen (2006), pretende-se incorporar ao estudo o elemento fonte de recurso, representando o lado da oferta de recursos. Porém, enquanto aqueles autores incorporaram o "acesso ao mercado de bonds" ao estudo da estrutura de capital, dada a importância e diferença que tais mercados têm para as empresas que analisaram, neste estudo, pretende-se incorporar o acesso que as empresas brasileiras tiveram a fontes diferenciadas de financiamento.

\section{PROCEDIMENTOS METODOLÓGICOS}

\subsection{Definição da amostra}

A definição da amostra, apresentada no Quadro 1, iniciou-se a partir da classificação Melhores e Maiores da Revista Exame. Foram anotadas todas as empresas de setores industriais que apareceram em qualquer um dos anos 2004, 2005 e 2006 e que eram negociadas na Bolsa de Valores, Mercadorias e Futuros de São Paulo - BM\&FBOVESPA. As empresas de serviços e de comércio não foram analisadas.

Em seguida, essas empresas foram separadas de acordo com a classificação NAICS (North American Industry Classification System). Finalmente, completou-se a amostra com empresas dos mesmos setores NAICS, que não estavam na Revista Exame, mas estavam na base de dados Economatica. Com estes critérios, foram obtidas 114 empresas. Durante o período estudado, algumas destas empresas tiveram os seus registros na Comissão de Valores Mobiliários - CVM cancelados, o que fez a amostra cair para 102 empresas. Como parte do trabalho dependia de informações das Notas Explicativas das Demonstrações Financeiras, foram retiradas da amostra empresas cujas Notas não detalhavam os seus financiamentos, fazendo a amostra totalizar 91 empresas.

Posteriormente, a análise das Notas Explicativas evidenciou empresas com insuficiência de informação, o que impediu uma classificação dos financiamentos com a qualidade necessária para as análises e argumentações decorrentes. Retiradas estas empresas, a amostra chegou a 83 empresas, que resultariam 830 observações ( 83 empresas, 10 anos). Porém, por uma série de 
motivos, principalmente pela insuficiência de informação para o cálculo de algumas variáveis para determinadas empresas em determinados anos, o número efetivo de observações foi menor que o potencial. Além de insuficiência de informações, empresas que apresentaram Patrimônio Líquido negativo em determinado ano, para esse ano, não tiveram os seus índices de endividamento calculados. Duas empresas (F. Guimarães e Aço Altona), por este motivo, não tiveram seus índices de endividamento calculados em todo o período, o que fez com que a amostra, para as análises de endividamento, inclusive para as regressões, tivesse 81 empresas.

De acordo com os procedimentos descritos acima, verifica-se que a amostra analisada neste estudo é intencional (não probabilística), impossibilitando a generalização dos resultados obtidos, o que se constitui em uma das limitações da pesquisa.

\begin{tabular}{|c|c|c|}
\hline Setores & $\begin{array}{l}\text { N. de } \\
\text { empresas }\end{array}$ & Empresas \\
\hline Abatedouros & 4 & Avipal, Minupar, Perdigão e Sadia (exceto 1997 - *4) \\
\hline Construção de edifícios residenciais & 3 & $\begin{array}{l}\text { Cyrela Realty, Gafisa (exceto } 1997 \text { e } 1998 \text { - *4) e Rossi } \\
\text { Resid }\end{array}$ \\
\hline $\begin{array}{l}\text { Extração minerais não metálicos; } \\
\text { extração petróleo e gás; mineração de } \\
\text { metais }\end{array}$ & 3 & Magnesita; Petrobras; Vale do Rio Doce \\
\hline Indústria de carrocerias e trailers & 3 & Marcopolo, Randon Part e Recrosul \\
\hline Indústria de produtos de plástico & 3 & Dixie Toga, Petropar e Sansuy \\
\hline $\begin{array}{l}\text { Indústria de produtos de madeira } \\
\text { compensada }\end{array}$ & 1 & Duratex \\
\hline $\begin{array}{l}\text { Indústria de produtos de petróleo e } \\
\text { carvão }\end{array}$ & 2 & Ipiranga Ref e Petr Manguinhos \\
\hline Indústria de autopeças & 9 & $\begin{array}{l}\text { Arteb, Fras-Le, lochp-Maxion (2001 a 2006), Mahle Metal } \\
\text { Leve, Plascar, Tupy, Wetzel, Wiest (exceto } 2006 \text { - *4) e } \\
\text { Riosulense }\end{array}$ \\
\hline Indústria de calçados & 4 & $\begin{array}{l}\text { Alpargatas, Cambuci, Vulcabras e Grendene (exceto de } \\
1997 \text { a } 2002-* 3 \text { ) }\end{array}$ \\
\hline Indústria de papel, celulose e papelão & 5 & $\begin{array}{l}\text { Aracruz, Klabin (exceto de } 1997 \text { a } 2000-* 1) \text {, Suzano } \\
\text { Papel (exceto de } 1997 \text { a } 2002 \text { - *1), Votorantim CP e Cel } \\
\text { Irani }\end{array}$ \\
\hline Indústria de roupas de malha & 1 & Cia Hering \\
\hline Indústria de roupas de tecido & 5 & $\begin{array}{l}\text { Coteminas, Karsten, Teka, Wembley, Buettner (2004 a } \\
\text { 2006) }\end{array}$ \\
\hline Indústria química & 8 & $\begin{array}{l}\text { Braskem, M\&G Poliester, Petroq Uniao, Pronor, Ultrapar, } \\
\text { Unipar, Suzano Petr (exceto de } 1997 \text { a } 2000-* 2 \text { ) e } \\
\text { Millennium }\end{array}$ \\
\hline Indústria química básica & 3 & Copesul, Elekeiroz e Politeno \\
\hline Outras indústrias de produtos de metal & 7 & $\begin{array}{l}\text { Caraiba Metais, Forjas Taurus, Paranapanema, CBC } \\
\text { Cartucho, Metal Iguacu, Metisa e Tekno (1997 a 2002) }\end{array}$ \\
\hline $\begin{array}{l}\text { Outras Indústrias: equip. aeroespacias; } \\
\text { equip de audio e video; fibras e } \\
\text { borrachas sintéticas; maq. agrícolas, } \\
\text { constr. e mineração; maq. industriais }\end{array}$ & 5 & $\begin{array}{l}\text { Embraer; Gradiente; Petroflex; Bardella; Inds Romi } \\
\text { (exceto } 1997-* 4 \text { ) }\end{array}$ \\
\hline 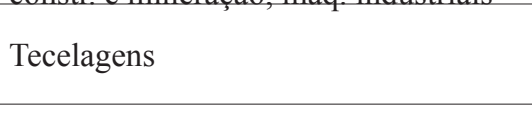 & 9 & $\begin{array}{l}\text { Cedro, Fab C Renaux, Inds Cataguases, Santanense, } \\
\text { Santista Textil, Tecel S Jose, Vicunha Textil, F Guimaraes } \\
\text { (exceto } 1997 \text { e } 2006-* 4 ; * 5 \text { ) e Schlosser }\end{array}$ \\
\hline \multirow[t]{2}{*}{$\begin{array}{l}\text { Transformação de aço em produtos de } \\
\text { aço }\end{array}$} & 8 & $\begin{array}{l}\text { Acos Villares, Arcelor Br, Confab, Gerdau (exceto } 1997 \\
\text { - 4), Gerdau Met (exceto } 1997 \text { - *4), Sid Nacional, } \\
\text { Usiminas (exceto } 1997 \text { e } 1998 \text { - *1) e Aco Altona }(* 5)\end{array}$ \\
\hline & 83 & \\
\hline
\end{tabular}

Quadro 1: Amostra

Notas: *1: anos retirados por divergência entre Notas Explicativas e Balanço Patrimonial; *2: a empresa passou 
a ser negociada em bolsa (e ter informação disponível) no início de negociação em 2001; *3: a empresa passou a ser negociada em bolsa (e ter informação disponível) no início de negociação em 2003; *4: a Nota Explicativa estava indisponível; *5: por apresentarem PL negativo em todo o período, efetivamente saíram das amostras para os estudos de endividamento.

Fontes: Revista Exame; Economatica; Comissão de Valores Mobiliários; e Demonstrações Financeiras das Empresas.

\subsection{Definição das variáveis}

Para alcance do objetivo da pesquisa, a partir do arcabouço teórico e metodológico existente para o estudo de empresas de países desenvolvidos, primeiramente, analisamse os principais determinantes de estrutura de capital de empresas brasileiras no período 1997-2006. Pretende-se entender se as variáveis comumente estudadas para explicar os níveis de endividamento de empresas em outros contextos (espaciais e temporais) aplicam-se ao caso brasileiro. Posteriormente, pretende-se explicar seus níveis de endividamento a partir da inclusão de variáveis que representam a oferta de fontes diferenciadas de financiamento.

Para construção das variáveis utilizadas no estudo, foram coletados dados do Balanço Patrimonial, da Demonstração de Resultados e indicadores de mercado das empresas utilizandose o banco de dados Economatica ${ }^{11}$. Na referida base, considerou-se as demonstrações contábeis consolidadas $^{12}$ de todas as companhias, em moeda original. Também foram coletados dados diretamente das notas explicativas dos relatórios financeiros das empresas, utilizando-se como fonte de dados a CVM, como será explicado a seguir.

A variável dependente analisada foi a relação entre o Passivo Oneroso e o Ativo PO/A. Compuseram o Passivo Oneroso os grupos da Economatica: Financiamentos de Curto Prazo, Debêntures de Curto Prazo, Financiamentos de Longo Prazo e Debêntures de Longo Prazo. Para os casos em que o Valor do Patrimônio Líquido da empresa se apresentava negativo, nenhuma variável dependente foi calculada, tendo sida tratada nas análises estatísticas como missing. Isto foi feito devido ao fato de que quando o Patrimônio Líquido da empresa é negativo, o indicador $\mathrm{PO} / \mathrm{A}$ que deveria variar entre 0 e $100 \%$, pode ficar acima de $100 \%$, visto que o Passivo Oneroso pode se tornar maior que o Ativo.

Após uma análise preliminar de todas as variáveis explicativas selecionadas, decidiu-se por eliminar do estudo àquelas que não se mostraram significativas ou que não se ajustaram a nenhum dos modelos de dados em painel. Este processo foi realizado mediante a inclusão das diversas variáveis em vários modelos de teste, análise dos coeficientes obtidos e respectivas significâncias. As variáveis eliminadas foram aquelas que não obtiveram significância estatística para seus coeficientes em nenhum dos modelos de teste ou que apresentaram menor poder explicativo que outras representativas do mesmo atributo. Ressalta-se que os softwares Eviews e Stata não apresentam um método específico para dados em painel que realize este tipo de procedimento.

Por meio deste procedimento, foram identificados os seguintes atributos (e variáveis) com um bom ajuste geral nos modelos que procuraram explicar os níveis de endividamento total: tamanho (logaritmo natural ${ }^{13}$ das vendas), tangibilidade (relação entre o imobilizado

11 www.economatica.com

12 Destaca-se que a literatura internacional favorece a utilização das demonstrações contábeis consolidadas. Para fins de comparação dos resultados, optou-se pela utilização de dados consolidados neste trabalho. 
líquido, excluída a reserva de reavaliação, e o ativo total), expectativas ou oportunidades de crescimento (relação entre o valor de mercado da ação e o seu valor contábil), rentabilidade (relação entre o lucro antes dos juros e o ativo total) e risco (beta dos ativos, equivalente ao beta das ações após a exclusão do efeito da alavancagem).

O beta dos ativos, extraído da base de dados Economatica, é obtido pela covariância dos retornos dos ativos com os retornos da carteira de mercado (Ibovespa) dividida pela variância dos retornos da carteira de mercado, considerando os últimos 60 meses. Visto que o beta obtido possui tanto o risco econômico (risco do negócio) quanto o risco financeiro (alavancagem), utilizou-se o beta desalavancado ${ }^{14}$ como medida de risco da empresa, sendo calculado da seguinte forma:

$$
\text { Risco }=\text { Beta "desalavancado" }=\frac{\text { Beta }}{1+(1-0,34) \times \frac{\mathrm{PO}}{\mathrm{PL}}}
$$

em que:

PO/PL: nível de endividamento dado pelo quociente passivo oneroso/patrimônio líquido; e 0,34: alíquota de imposto de renda e contribuição social considerada para as empresas da amostra. Dessa forma, o risco financeiro foi excluído do coeficiente, permanecendo apenas o risco do negócio.

Posteriormente, foram incorporadas variáveis representativas do atributo "acesso a fontes diferenciadas de financiamento" no modelo inicial de dados em painel com "variáveis clássicas" (ou variáveis usualmente empregadas nos modelos de estrutura de capital). Para que fosse levantado o acesso a fontes diferenciadas (com taxas subsidiadas), cujas taxas de juros são menores que as taxas de mercado, foram utilizadas as informações constantes principalmente nas Notas Explicativas dos relatórios financeiros das empresas. A partir destas Notas Explicativas, os financiamentos das empresas foram classificados em quatro grupos: i) Tipo $1 \mathrm{~N}$ - linhas diferenciadas em moeda nacional; ii) Tipo 1E - linhas diferenciadas em moeda estrangeira; iii) Tipo $2 \mathrm{~N}$ - linhas de mercado em moeda nacional; e iv) Tipo 2E - linhas de mercado em moeda estrangeira.

A classificação entre Tipo 1 (diferenciada) e Tipo 2 (de mercado) foi possível a partir da análise da instituição financiadora, da origem dos recursos e/ou do indexador da operação. Como exemplos de financiamentos Tipo 1, podem ser citados os que foram classificados a partir: i) da instituição financiadora (BNDES, Banco Regional de Desenvolvimento do Extremo Sul - BRDE, Financiadora de Estudos e Projetos - FINEP, etc.); ii) da origem dos recursos (Finame, Empréstimos do Governo Federal - EGF, etc.); ou iii) do indexador (Taxa de Juros de Longo Prazo - TJLP, Taxa Referencial - TR, etc.). Finalmente, a classificação entre moeda nacional e estrangeira foi realizada a partir: i) da separação que as empresas fazem nas próprias Notas Explicativas entre os dois grupos; ii) da informação da moeda do financiamento (Real, Dólar, Euro, etc.); ou iii) do indexador (London Interbank Offered Rate - Libor, variações cambiais, etc.).

Após o levantamento e classificação de todos os financiamentos de cada empresa em

\footnotetext{
13 Utilizou-se o logaritmo do valor absoluto com o intuito de reduzir problemas de heterocedasticidade dos resíduos devido à ordem de grandeza da variável e de possíveis outliers de valores de receita considerando determinadas empresas muito grandes ou muito pequenas na amostra.

14 O procedimento realizado para desalavancar o beta está fundamentado na literatura existente (Ross, et al., 2002; Assaf Neto, 2007; Minardi et al., 2007; e Assaf Neto, et al., 2008).
} 
um dos quatro grupos, foi calculada a participação de cada grupo no total do financiamento de cada empresa, de modo que cada variável assumisse valores entre 0 e 1 e que a soma dos quatro grupos totalizasse 1 .

\subsection{Tratamento dos dados}

Em relação à parte estatística, uma vez que o banco de dados elaborado possui a característica de combinar observações de várias empresas ao longo de um determinado período de tempo, utilizou-se o método de análise de dados em painel. Dois métodos comuns para estimar modelos de dados em painel com efeitos não observados são os métodos de efeitos fixos e efeitos aleatórios. O efeito fixo permite a existência de correlação entre as características idiossincráticas das empresas e o vetor de variáveis independentes. Em outras palavras, possibilita-se que as características não-observáveis (conseqüentemente não adicionadas ao modelo) que diferenciam uma empresa de outra estejam correlacionadas com uma ou mais variáveis independentes incluídas no modelo. Já o modelo de efeitos aleatórios exige que se assuma que tal correlação é zero, ou seja: todas as formas de distinção entre empresas que não foram incluídas no modelo não possuem correlação com qualquer variável independente, ficando no termo de erro composto $\left(v_{i t}\right)$.

O modelo de efeitos fixos permite que o intercepto varie para cada observação, levando em conta a natureza específica da empresa, porém, considera-se que os coeficientes angulares são constantes entre elas. Sua equação pode ser descrita da seguinte forma:

$$
y_{i t}=\beta_{0 i}+\beta_{1} x_{1 i t}+\ldots+\beta_{k} x_{k i t}+u_{i t}, t=1,2, \ldots, T
$$

Já o modelo de efeitos aleatórios pode ser descrito como:

$$
y_{i t}=\beta_{0}+\beta_{1} x_{1 i t}+\ldots+\beta_{k} x_{k i t}+v_{i t}
$$

em que:

$y_{i t}$ : variável dependente, $\beta_{0}$ : intercepto, $\beta_{k}$ : coeficiente angular da reta de regressão, $x_{i t}$ : variáveis explicativas, $v_{i t}$ (termo de erro composto), sendo igual a: $a_{i}$ (efeito não observado de cada empresa $)+u_{i t}$ (erros idiossincráticos).

De acordo com Wooldridge (2002), uma forma de decidir entre os modelos é comparar as estimativas dos modelos de efeitos fixos e de efeitos aleatórios visando verificar se existe correlação entre os fatores não observados $\left(a_{i}\right)$ e as variáveis explicativas $\left(x_{i t}\right)$, assumindo que os erros idiossincráticos e as variáveis explicativas são não-correlacionados ao longo do tempo. Para tanto, aplica-se o teste de Hausman, em que a hipótese nula a ser testada é a de que a diferença entre os coeficientes dos efeitos fixos e aleatórios não é sistemática. Visto que o modelo de efeitos fixos seria consistente quando $a_{i}$ e $x_{i t}$ fossem correlacionados, mas o modelo de efeitos aleatórios seria inconsistente, uma diferença estatística significativa é interpretada como evidência contra a suposição de efeitos aleatórios. Assim, caso haja diferença significativa entre os dois modelos, tal diferença é interpretada como uma evidência em favor da estimação por efeitos fixos, rejeitando-se a hipótese nula.

Adicionalmente, buscou-se verificar se um modelo sem tais efeitos (modelo restrito ou 
pooling) seria mais adequado para tratamento da amostra analisada. Neste modelo, todos os dados (em corte transversal e séries temporais) são combinados e então se estima o modelo por Mínimos Quadrados Ordinários (MQO), ou seja, o modelo representa uma regressão em sua forma mais convencional, de acordo com Fávero et al. (2009). Para análise da possível adequação do modelo pooling, utilizou-se o teste de Breusch e Pagan (1980) com uso da estatística LM. A hipótese nula a ser testada é a de que a variância dos resíduos que refletem diferenças individuais é igual a zero, neste caso, o modelo pooling seria mais adequado. Caso a hipótese nula seja rejeitada, considera-se que o modelo mais adequado seria o de efeitos aleatórios.

Dada a possibilidade de existência de heteroscedasticidade e autocorrelação dos resíduos, utilizou-se o método de Newey-West (Newey e West, 1987) para obtenção de parâmetros robustos. As variáveis explicativas foram utilizadas com defasagem temporal de um período $(t-1)$.

\section{ANÁLISE DOS RESULTADOS}

A Tabela 1 apresenta as estatísticas descritivas da variável dependente (endividamento total) e das variáveis explicativas utilizadas nos modelos com defasagem temporal de um período. Entre outros, destacam-se nesta tabela os seguintes números: em termos médios, as empresas apresentaram um nível de $28,5 \%$ de endividamento total; tamanho médio de 13 (logaritmo natural das vendas); 39\% de ativos imobilizados; $7 \%$ de rentabilidade dos ativos; $34 \%$ de financiamentos em linhas diferenciadas (Tipo 1); e $46 \%$ de financiamentos de mercado em moeda estrangeira (Tipo 2E).

Tabela 1: Estatística descritiva das variáveis

\begin{tabular}{c|c|c|c|c|c}
\hline Variáveis & $\begin{array}{c}\text { Número de } \\
\text { observações }\end{array}$ & Média & $\begin{array}{c}\text { Desvio } \\
\text { padrão }\end{array}$ & Mínimo & Máximo \\
\hline PO / A & 712 & 0,285 & 0,155 & 0,000 & 0,813 \\
\hline Tamanho & 701 & 13,092 & 1,589 & 9,181 & 18,733 \\
\hline Tangibilidade & 701 & 0,391 & 0,153 & 0,002 & 0,797 \\
\hline Oportunidades de crescimento & 553 & 1,417 & 4,245 & 0,030 & 87,400 \\
\hline Rentabilidade & 701 & 0,071 & 0,121 & $-1,108$ & 0,643 \\
\hline Risco & 494 & 0,343 & 0,234 & $-0,184$ & 1,359 \\
\hline Tipo 1 & 701 & 0,344 & 0,286 & 0,000 & 1,000 \\
\hline Tipo 2E & 701 & 0,458 & 0,311 & 0,000 & 1,000 \\
\hline
\end{tabular}

Notas: Variável dependente: relação entre o Passivo Oneroso e o Ativo (PO/A). PO: Passivo Oneroso; A: Ativo; Tipo 1: linhas diferenciadas; Tipo 2E: linhas de mercado em moeda estrangeira.

Fontes: Economatica; Demonstrações Financeiras das Empresas.

Conforme exposto anteriormente, o principal objetivo deste trabalho é entender a composição dos financiamentos de empresas brasileiras e analisar a participação de fontes diferenciadas de financiamento em suas estruturas de capital. Para tanto, os financiamentos das empresas da amostra foram classificados entre 1 (linha diferenciada) e 2 (linha de mercado) e entre N (moeda nacional) e E (moeda estrangeira), como pode ser verificado na Tabela 2. 
Tabela 2: Financiamentos por Tipo (1N, 1E, 2N e 2E)

\begin{tabular}{c|c|c|c|c|c|c|c|c|c|c}
\hline \multicolumn{10}{c}{ Média das empresas da amostra. } \\
\hline $\begin{array}{c}\text { Financiam } \\
\text { entos }\end{array}$ & $\mathbf{1 9 9 7}$ & $\mathbf{1 9 9 8}$ & $\mathbf{1 9 9 9}$ & $\mathbf{2 0 0 0}$ & $\mathbf{2 0 0 1}$ & $\mathbf{2 0 0 2}$ & $\mathbf{2 0 0 3}$ & $\mathbf{2 0 0 4}$ & $\mathbf{2 0 0 5}$ & $\mathbf{2 0 0 6}$ \\
\hline Tipo 1N & $31 \%$ & $31 \%$ & $28 \%$ & $30 \%$ & $30 \%$ & $26 \%$ & $29 \%$ & $30 \%$ & $29 \%$ & $33 \%$ \\
\hline Tipo 1E & $3 \%$ & $5 \%$ & $7 \%$ & $7 \%$ & $7 \%$ & $7 \%$ & $5 \%$ & $4 \%$ & $3 \%$ & $2 \%$ \\
\hline Tipo 2N & $14 \%$ & $15 \%$ & $14 \%$ & $15 \%$ & $19 \%$ & $21 \%$ & $23 \%$ & $25 \%$ & $30 \%$ & $27 \%$ \\
\hline Tipo 2E & $52 \%$ & $49 \%$ & $52 \%$ & $48 \%$ & $44 \%$ & $45 \%$ & $43 \%$ & $41 \%$ & $38 \%$ & $38 \%$ \\
\hline Tipo 1 & $34 \%$ & $36 \%$ & $34 \%$ & $37 \%$ & $37 \%$ & $34 \%$ & $34 \%$ & $34 \%$ & $32 \%$ & $35 \%$ \\
\hline Tipo 2 & $66 \%$ & $64 \%$ & $66 \%$ & $63 \%$ & $63 \%$ & $66 \%$ & $66 \%$ & $66 \%$ & $68 \%$ & $65 \%$ \\
\hline Tipo N & $45 \%$ & $46 \%$ & $42 \%$ & $46 \%$ & $49 \%$ & $47 \%$ & $52 \%$ & $55 \%$ & $59 \%$ & $60 \%$ \\
\hline Tipo E & $55 \%$ & $54 \%$ & $58 \%$ & $54 \%$ & $51 \%$ & $53 \%$ & $48 \%$ & $45 \%$ & $41 \%$ & $40 \%$ \\
\hline Total Geral & $100 \%$ & $100 \%$ & $100 \%$ & $100 \%$ & $100 \%$ & $100 \%$ & $100 \%$ & $100 \%$ & $100 \%$ & $100 \%$ \\
\hline
\end{tabular}

Notas: para se chegar aos percentuais apresentados na tabela, primeiramente foi calculado o percentual de cada tipo em cada empresa e, depois, calculou-se a média dos percentuais de todas as empresas; Tipo $1 \mathrm{~N}$ : linhas diferenciadas em moeda nacional; Tipo 1E: linhas diferenciadas em moeda estrangeira; Tipo $2 \mathrm{~N}$ : linhas de mercado em moeda nacional; Tipo 2E: linhas de mercado em moeda estrangeira; Tipo 1: linhas diferenciadas; Tipo 2: linhas de mercado; Tipo N: linhas em moeda nacional; Tipo E: linhas em moeda estrangeira.

Fontes: Economatica; Demonstrações Financeiras das Empresas.

Esta análise evidencia o que as empresas brasileiras fizeram para escapar dos altos juros do período estudado. Em primeiro lugar, tiveram como estratégia a utilização de recursos em moeda estrangeira, que muitas vezes têm como base de custo de capital a Libor (London Interbank Offered Rate), menor que as bases das taxas internas.

Em segundo lugar, cabe destacar o uso de linhas diferenciadas (Tipo 1), que são aquelas com taxas de juros formadas a partir de critérios que não os de mercado e que podem ser consideradas subsidiadas, como as linhas de bancos de desenvolvimento, majoritariamente as do BNDES, e as linhas oficiais de Crédito Rural. No período estudado, estas linhas representaram de $32 \%$ a $37 \%$ da composição do financiamento das empresas da amostra. Interessante é a comparação da participação dos financiamentos Tipo $1 \mathrm{~N}$, com taxas de juros diferenciadas (subsidiadas) em moeda nacional, com a participação dos financiamentos Tipo 2N, que representam as linhas de mercado em moeda nacional. Ao longo de praticamente todo o período estudado, as linhas de mercado em moeda nacional que, supostamente, deveriam predominar sobre as demais linhas no financiamento das empresas aqui instaladas, tiveram uma participação menor do que as linhas diferenciadas em moeda nacional (Tipo 1N). No início do período, a participação das linhas Tipo $1 \mathrm{~N}$ (diferenciadas) foi praticamente o dobro da participação das linhas Tipo $2 \mathrm{~N}$ (de mercado).

Esta estratégia pode ser compreendida ao se analisar as taxas de juros ocorridas no período estudado (Tabela 3): as taxas básicas do BNDES (TJLP - Taxa de Juros de Longo Prazo) e a taxa do Crédito Rural sempre se apresentaram muito abaixo das taxas do Interbancário Brasileiro (Depósitos Interfinanceiros - DI), que representa a base das taxas de juros para a economia empresarial. Adicionalmente, as captações internacionais em moeda estrangeira, cuja base era a Libor (London Interbank Offered Rate), menor que o Cupom Cambial, que pode ser tomado como base do custo de capital do mercado doméstico em dólares, colocaram-se também 
como uma alternativa às empresas brasileiras.

Tabela 3: Taxas de juros (em final de período)

\begin{tabular}{c|c|c|c|c|c}
\hline & DI & TJLP & CR & Libor & CC \\
\hline 1997 & $38,73 \%$ & $9,25 \%$ & $9,50 \%$ & $5,10 \%$ & $20,13 \%$ \\
\hline 1998 & $29,03 \%$ & $11,66 \%$ & $8,75 \%$ & $5,10 \%$ & $14,72 \%$ \\
\hline 1999 & $18,83 \%$ & $13,22 \%$ & $8,75 \%$ & $6,50 \%$ & $9,65 \%$ \\
\hline 2000 & $15,72 \%$ & $9,75 \%$ & $8,75 \%$ & $6,00 \%$ & $8,50 \%$ \\
\hline 2001 & $19,02 \%$ & $10,00 \%$ & $8,75 \%$ & $2,44 \%$ & $5,62 \%$ \\
\hline 2002 & $24,83 \%$ & $10,00 \%$ & $8,75 \%$ & $1,45 \%$ & $21,00 \%$ \\
\hline 2003 & $16,27 \%$ & $11,00 \%$ & $8,75 \%$ & $1,46 \%$ & $2,68 \%$ \\
\hline 2004 & $17,76 \%$ & $9,75 \%$ & $8,75 \%$ & $3,10 \%$ & $2,93 \%$ \\
\hline 2005 & $17,99 \%$ & $9,75 \%$ & $8,75 \%$ & $4,84 \%$ & $4,39 \%$ \\
\hline 2006 & $13,17 \%$ & $6,85 \%$ & $8,75 \%$ & $5,33 \%$ & $5,43 \%$ \\
\hline
\end{tabular}

Notas: DI: taxa média dos Depósitos Interfinanceiros; TJLP: Taxa de Juros de Longo Prazo; CR: taxa das operações de Crédito Rural; Libor: London Interbank Offered Rate; e CC: taxa do Cupom Cambial.

Fontes: Câmara de Liquidação e Custódia - CETIP (www.cetip.com.br); Banco Nacional de Desenvolvimento Econômico e Social - BNDES (www.bndes.gov.br); Banco Central do Brasil (www.bcb.gov.br); British Bankers Association - BBB (www.bba.org.uk); BM\&FBOVESPA (www.bmfbovespa.com.br).

Nesse contexto, claramente vê-se o que empresas brasileiras fizeram para contornar as altas taxas de juros: usaram linhas de financiamento em moeda que não a brasileira (linhas Tipo E), recorreram às instituições que o país ofereceu (linhas Tipo 1) e escaparam das linhas de mercado em moeda nacional (linhas Tipo $2 \mathrm{~N}$ ). Logo, defende-se que o acesso que as empresas tiveram a linhas diferenciadas (Tipo 1) e a linhas em moeda estrangeira (Tipo E) foi fundamental para as suas decisões de financiamento, podendo-se especular que tal acesso foi importante também para as suas decisões de investimento.

Após a classificação dos financiamentos das empresas, realizou-se a análise do endividamento total por meio da elaboração de dois modelos: i) considerando-se apenas variáveis clássicas; e ii) com a inclusão das variáveis Tipo 1 e Tipo $2 \mathrm{E}$.

$\mathrm{Na}$ Tabela 4, a seguir, apresentam-se os resultados da análise do endividamento total $(\mathrm{PO} / \mathrm{A})$ a partir de variáveis clássicas. Nesta tabela é possível visualizar os resultados dos modelos de efeitos fixos, efeitos aleatórios e efeitos fixos com erros-padrão robustos para heterocedasticidade e autocorrelação pelo método de Newey-West.

Ressalta-se que o resultado do teste de Breusch-Pagan rejeitou a hipótese nula de que a variância dos resíduos é igual a zero, desfavorecendo a utilização do modelo pooling. O teste de Hausman também rejeitou a hipótese nula de que a diferença entre os coeficientes do modelo de efeitos fixos e do modelo de efeitos aleatórios não é sistemática, apontando a razoabilidade do modelo de efeitos fixos. Assim sendo, analisa-se o modelo de efeitos fixos para a presente amostra.

De acordo com Gujarati (2006), a escolha dentre os modelos de efeitos fixos ou de efeitos aleatórios depende da pressuposição assumida sobre a provável correlação entre o componente de erro individual relacionado ao corte transversal (ou seja, relacionado a cada empresa) e as variáveis explicativas. Caso se assuma que o componente de erro individual (ou 
as características não-observáveis de cada empresa) não seja correlacionado com as variáveis explicativas, o modelo de efeitos aleatórios pode ser considerado adequado, caso contrário, o modelo de efeitos fixos pode ser preferível. Assim sendo, se as características não-observáveis de cada empresa forem correlacionadas com uma ou mais variáveis explicativas do modelo, os estimadores do modelo de efeitos aleatórios serão viesados, o que não ocorreria com a utilização do modelo de efeitos fixos.

O teste de Hausman, realizado neste trabalho, é um teste formal para auxiliar na escolha dentre os modelos, apontando para a adequação do modelo de efeitos fixos. No entanto, a utilização do modelo de efeitos fixos também se justifica pela natureza deste estudo. Considerando que diversos fatores podem influenciar as decisões de financiamento das empresas e, consequentemente, determinar suas estruturas de capital, é de se esperar que existam características não observadas de cada empresa, ou seja, variáveis omitidas, que possivelmente apresentariam alguma correlação com as variáveis explicativas utilizadas no modelo. Portanto, julga-se que a utilização do modelo de efeitos fixos aumente a validade e confiabilidade dos resultados obtidos. De qualquer forma, foram apresentados os coeficientes estimados pelos dois modelos, sendo possível notar pouca diferença dos valores dos coeficientes em termos absolutos e nenhuma mudança em relação aos sinais.

Como ressaltado na metodologia, utilizou-se o método de Newey-West para obtenção de parâmetros robustos. Gujarati (2006) afirma que, ao comparar as duas regressões, verifica-se que os coeficientes estimados e o $\mathrm{R}^{2}$ dos modelos permanecem inalterados, mas é importante destacar que os erros-padrão de Newey-West são maiores que os obtidos por meio dos Mínimos Quadrados Ordinários (MQO). Isso mostra que os MQO subestimaram de fato os verdadeiros erros-padrão.

Tabela 4: Análise do endividamento total a partir de variáveis clássicas

\begin{tabular}{|c|c|c|c|c|c|c|c|c|c|}
\hline \multirow[b]{2}{*}{$\begin{array}{l}\text { Variáveis } \\
\text { independentes }\end{array}$} & \multicolumn{3}{|c|}{ Efeitos fixos (EF) } & \multicolumn{3}{|c|}{ Efeitos aleatórios (EA) } & \multicolumn{3}{|c|}{ Efeitos fixos (EF), NW } \\
\hline & beta & dp & p-val & beta & dp & p-val & beta & dp & p-val \\
\hline Tamanho & $-0,029$ & 0,009 & 0,002 & $-0,003$ & 0,007 & 0,658 & $-0,029$ & 0,010 & 0,003 \\
\hline Tangibilidade & 0,321 & 0,067 & 0,000 & 0,369 & 0,056 & 0,000 & 0,321 & 0,074 & 0,000 \\
\hline $\begin{array}{l}\text { Oportunidades } \\
\text { de crescimento }\end{array}$ & $-0,002$ & 0,001 & 0,038 & $-0,002$ & 0,001 & 0,047 & $-0,002$ & 0,001 & 0,016 \\
\hline Rentabilidade & $-0,165$ & 0,059 & 0,006 & $-0,196$ & 0,059 & 0,001 & $-0,165$ & 0,063 & 0,009 \\
\hline Risco & $-0,158$ & 0,023 & 0,000 & $-0,151$ & 0,023 & 0,000 & $-0,158$ & 0,025 & 0,000 \\
\hline Constante & 0,635 & 0,136 & 0,000 & 0,269 & 0,094 & 0,004 & & & \\
\hline $\mathrm{n}^{0} \mathrm{o}$ observações & 445 & & & \multicolumn{2}{|c|}{$\mathrm{n}^{\mathrm{o}}$ observações } & 445 & \multicolumn{2}{|c|}{$\mathrm{n}^{\mathrm{o}}$ observações } & 443 \\
\hline Prob $>F$ & 0,000 & & & \multicolumn{2}{|c|}{ Prob $>$ chi 2} & 0,000 & \multicolumn{2}{|l|}{ Prob $>F$} & 0,000 \\
\hline $\mathrm{R}^{2}$ & 0,238 & & & \multicolumn{2}{|l|}{$\mathrm{R}^{2}$} & 0,222 & \multicolumn{2}{|l|}{$\mathrm{R}^{2}$} & 0,238 \\
\hline
\end{tabular}

Breusch and Pagan Lagrangian multiplier test for random effects:

Test: $\operatorname{Var}(\mathrm{u})=0$

$\operatorname{chi} 2(1)=632,30$

Prob $>$ chi $2=0,000$

\section{Hausman fixed}

Test: Ho: difference in coefficients not systematic

$\operatorname{chi} 2(5)=(b-B)^{\prime}\left[\left(V \_b-V \_B\right)^{\wedge}(-1)\right](b-B)=6244,29$

Prob $>$ chi $2=0,000$ 
Notas: Variável dependente: PO/A - Modelo com variáveis clássicas. Regressões com dados em painel - Efeitos Fixos, Efeitos Aleatórios e Efeitos Fixos com erros-padrão robustos para heterocedasticidade e autocorrelação pelo método de Newey-West. Variável dependente: relação entre o Passivo Oneroso e o Ativo (PO/A). Variáveis explicativas defasadas (em $t$-1). Beta: coeficientes; dp: desvio padrão; p-val: nível de significância do coeficiente; Prob>F, Prob>chi2: nível de significância do modelo; $\mathrm{R}^{2}$ : coeficiente de explicação do modelo; (EF), NW: efeitos fixos com erros-padrão robustos para heterocedasticidade e autocorrelação pelo método de Newey-West; regressões foram obtidas a partir do software Stata.

Fontes: Economatica; Demonstrações Financeiras das Empresas.

Em termos gerais, quando se analisa o nível de endividamento das empresas a partir das variáveis clássicas selecionadas, destacam-se os seguintes resultados: o poder de explicação do modelo ficou na em torno de $24 \%$; as variáveis apresentaram coeficientes estatisticamente significativos; e, exceto a variável tamanho (ln Vendas), todas as outras apresentaram o sinal esperado.

O resultado para a variável tamanho merece atenção. A variável apresenta sinal não esperado e coeficientes estatística e economicamente significativos. Parece-nos que o sinal e o efeito da variável tamanho são mais estatísticos do que econômicos. Tal conclusão parcial impede-nos de traçar conclusões mais precisas do relacionamento entre a variável tamanho e o nível de endividamento total.

A variável tangibilidade, por outro lado, apresenta resultados bastante satisfatórios: o sinal é o esperado, reforçando o papel de redutor de conflitos de agência que têm os ativos fixos, e a sua contribuição é economicamente significativa para o coeficiente de endividamento total. Os resultados encontrados para esta variável confirmam o esperado pela literatura e vão ao encontro à argumentação traçada anteriormente. A relação positiva entre ativos tangíveis e endividamento tem forte suporte na literatura. Smith Jr. e Warner (1979a), por exemplo, destacaram o papel do penhor sobre os ativos como forma de reduzir a "substituição de projetos" e de evitar novos financiamentos sobre os mesmos ativos. Para Titman e Wessels (1988), firmas que têm ativos que podem ser dados em garantia aproveitam esta vantagem e emitem mais dívidas. Rajan e Zingales (1995) ainda destacam que a existência de ativos tangíveis aumenta a disposição de credores, por possuírem maior valor em caso de liquidação da empresa e, como servem de garantia para operações financeiras, diminuem os custos de agência.

Especificamente em relação ao caso brasileiro, os resultados encontrados confirmam a importância da existência de ativos que podem ser dados em penhor no financiamento das empresas ao longo do período estudado, caracterizado por (1) altas taxas de juros, (2) presença modesta de dívidas de longo prazo oriundas de emissão de títulos no mercado de capitais, (3) financiamento bancário voltado para o curto prazo e (4) existência de linhas diferenciadas (como BNDES) repassadas pelo próprio sistema bancário.

Paradoxalmente, a combinação de altas taxas de juros do período e uma parcela de curto prazo relevante dos financiamentos potencializava o risco dos financiamentos (como o risco de liquidez e de inadimplência). Para mitigar estes riscos, sabe-se que parte do financiamento das empresas brasileiras se estruturou sobre penhores e hipotecas. Além de exigência natural em algumas linhas que repassavam (hipoteca e/ou penhor em uma série de linhas do BNDES e penhor nas operações de Crédito Rural), os bancos também exigiam garantias de ativos reais em operações com os seus recursos próprios.

Em relação à variável oportunidades de crescimento, o sinal é negativo e estatisticamente significativo. O sinal encontrado confirma a argumentação elaborada para esta variável a partir da literatura consultada (Jensen, 1986; Titman e Wessels, 1988; Demirgüç-Kunt e Maksimovic, 
1999; e Barclay et al., 2003): (1) credores são menos simpáticos a financiarem empresas com maiores taxas de crescimento, pois se defrontam com maiores conflitos de agência, particularmente no que tange ao risco de sub-investimento; (2) as oportunidades de crescimento geram valor, mas não geram ativos fixos que possam ser hipotecados; e (3) o papel da dívida em controlar o uso inadequado do fluxo de caixa livre em firmas com alta taxa de crescimento é pequeno. Entretanto, os valores médios e os coeficientes encontrados para esta variável não produzem resultados econômicos expressivos.

Para a variável rentabilidade, conforme visto, há argumentação para qualquer sinal. O sinal encontrado corrobora a argumentação em direção à teoria de pecking order (Myers, 1984; Myers e Majluf, 1984; Myers, 2001), em que firmas mais rentáveis geram mais recursos internos e, por isso, recorrem menos a recursos de terceiros. Conforme mencionado, as variáveis explicativas foram defasadas no tempo (em $t-1$ ), ou seja, as variáveis explicativas em $t-1$ foram usadas para explicar as variáveis dependentes em $t$. Tal metodologia permitiu confirmar a importância que Titman e Wessels (1988) registraram sobre o papel da rentabilidade passada na determinação da estrutura de capital da firma. Apesar do sinal negativo e dos resultados estatísticos significativos, que permitiram esta argumentação, a contribuição econômica desta variável não foi muito expressiva.

Finalmente, a variável risco apresentou contribuição interessante, apresentando significância estatística e econômica. O sinal negativo encontrado permite argumentar, sob as ressalvas que seguem, que empresas menos arriscadas, com menor probabilidade de falência, conseguem maior acesso a recursos de terceiros.

Se aceitarmos o Beta "desalavancado" como uma boa proxy para o atributo risco e também como substituto para as medidas tradicionais de risco, como o desvio padrão do fluxo de lucros, podemos afirmar que os resultados aqui encontrados e a argumentação elaborada no parágrafo anterior têm suporte no texto teórico de Kane et al. (1985), base para vários trabalhos empíricos como o de Stohs e Mauer (1996). Para Kane et al. (1985), um menor desvio padrão (dos retornos dos ativos) resulta num maior nível de endividamento, uma vez que diminui a probabilidade de falência. Myers (1984) também afirma que em empresas mais arriscadas, a probabilidade de falência é maior, reduzindo a capacidade de financiamento destas empresas e levando a uma relação negativa entre risco e alavancagem.

No Brasil, Medeiros e Daher (2008) analisaram a estrutura de capital de companhias listadas na BM\&FBovespa e encontraram os mesmos sinais para as variáveis tangibilidade e rentabilidade, onde empresas mais lucrativas são menos alavancadas, pois teriam recursos gerados internamente disponíveis para uso, bem como empresas com mais ativos tangíveis são menos alavancadas, afirmando que estas empresas poderiam emitir novas ações a preços justos, não necessitando emitir dívida para se financiarem.

Albanez e Valle (2009) também analisaram a estrutura de capital de companhias abertas brasileiras e destacaram os coeficientes e sinais obtidos com as variáveis tangibilidade e risco, os quais se mostraram persistentes e confirmaram a relação esperada com a alavancagem. A variável tangibilidade apresentou coeficiente positivo e a variável risco apresentou coeficiente negativo, ambos foram os coeficientes mais significativos e expressivos economicamente, como nesta pesquisa.

Posteriormente, foram incorporadas as variáveis Tipo 1 e Tipo $2 \mathrm{E}$ nas regressões anteriores, para análise do seu impacto no endividamento total (PO/A) das empresas, como apresentado na Tabela 5. Neste modelo, o resultado do teste de Breusch-Pagan também apontou para a não utilização do modelo pooling e o teste de Hausman favoreceu o modelo de efeitos 
fixos. Assim sendo, analisa-se o modelo de efeitos fixos e efeitos fixos com erros-padrão robustos para heterocedasticidade e autocorrelação pelo método de Newey-West.

Tabela 5: Análise do endividamento total com adição de variáveis "Tipos"

\begin{tabular}{|c|c|c|c|c|c|c|c|c|c|}
\hline & \multicolumn{3}{|c|}{ Efeitos fixos (EF) } & \multicolumn{3}{|c|}{ Efeitos aleatórios (EA) } & \multicolumn{3}{|c|}{ Efeitos fixos (EF), NW } \\
\hline $\begin{array}{l}\text { Variáveis } \\
\text { independentes }\end{array}$ & beta & dp & p-val & beta & dp & p-val & beta & dp & p-val \\
\hline Tamanho & $-0,029$ & 0,009 & 0,002 & $-0,004$ & 0,007 & 0,580 & $-0,029$ & 0,009 & 0,002 \\
\hline Tangibilidade & 0,304 & 0,067 & 0,000 & 0,357 & 0,056 & 0,000 & 0,304 & 0,072 & 0,000 \\
\hline $\begin{array}{l}\text { Oportunidades } \\
\text { de crescimento }\end{array}$ & $-0,002$ & 0,001 & 0,034 & $-0,002$ & 0,001 & 0,051 & $-0,002$ & 0,001 & 0,012 \\
\hline Rentabilidade & $-0,196$ & 0,060 & 0,001 & $-0,220$ & 0,059 & 0,000 & $-0,196$ & 0,062 & 0,002 \\
\hline Risco & $-0,164$ & 0,023 & 0,000 & $-0,156$ & 0,023 & 0,000 & $-0,164$ & 0,024 & 0,000 \\
\hline Tipo 1 & 0,095 & 0,031 & 0,002 & 0,070 & 0,030 & 0,019 & 0,095 & 0,036 & 0,009 \\
\hline Tipo 2E & 0,060 & 0,030 & 0,044 & 0,059 & 0,028 & 0,036 & 0,060 & 0,035 & 0,085 \\
\hline Constante & 0,586 & 0,138 & 0,000 & 0,235 & 0,096 & 0,014 & & & \\
\hline $\mathrm{n}^{\mathrm{o}}$ observações & \multicolumn{3}{|l|}{445} & \multicolumn{2}{|c|}{$\mathrm{n}^{\mathrm{o}}$ observações } & 445 & \multicolumn{2}{|c|}{$\mathrm{n}^{\mathrm{o}}$ observações } & 443 \\
\hline Prob $>F$ & \multicolumn{3}{|l|}{0,000} & \multicolumn{2}{|c|}{ Prob $>$ chi 2} & 0,000 & \multicolumn{2}{|c|}{ Prob $>F$} & 0,000 \\
\hline $\mathrm{R}^{2}$ & \multicolumn{3}{|l|}{0,257} & \multicolumn{2}{|c|}{$\mathrm{R}^{2}$} & 0,240 & \multicolumn{2}{|l|}{$\mathrm{R}^{2}$} & 0,257 \\
\hline
\end{tabular}

Breusch and Pagan Lagrangian multiplier test for random effects:

Test: $\operatorname{Var}(\mathrm{u})=0$

$\operatorname{chi} 2(1)=613,77$

Prob $>$ chi $2=0,000$

Hausman fixed

Test: Ho: difference in coefficients not systematic

$\operatorname{chi} 2(7)=(\mathrm{b}-\mathrm{B})^{\prime}\left[\left(\mathrm{V} \_\mathrm{b}-\mathrm{V} \_\mathrm{B}\right)^{\wedge}(-1)\right](\mathrm{b}-\mathrm{B})=2332,59$

Prob $>$ chi $2=0,000$

Notas: Variável dependente: PO/A - Modelo com adição de variáveis Tipos. Regressões com dados em painel - Efeitos Fixos, Efeitos Aleatórios e Efeitos Fixos com erros-padrão robustos para heterocedasticidade e autocorrelação pelo método de Newey-West. Variável dependente: relação entre o Passivo Oneroso e o Ativo (PO/A). Variáveis explicativas defasadas (em $t$-1). Tipo 1: linhas diferenciadas; Tipo 2E: linhas de mercado em moeda estrangeira; beta: coeficientes; dp: desvio padrão; p-val: nível de significância do coeficiente; Prob $>F$, Prob>chi2: nível de significância do modelo; $\mathrm{R}^{2}$ : coeficiente de explicação do modelo; (EF), NW: efeitos fixos com erros-padrão robustos para heterocedasticidade e autocorrelação pelo método de Newey-West; regressões foram obtidas a partir do software Stata.

Fontes: Economatica; Demonstrações Financeiras das Empresas.

Argumenta-se que o acesso a linhas de financiamento com taxas de juros diferenciadas (subsidiadas), como são as linhas do BNDES, produz impacto na estrutura de financiamento das empresas. Por construção das variáveis (Tipo $1=1 \mathrm{~N}+1 \mathrm{E}$; Tipo $\mathrm{E}=1 \mathrm{E}$ e $2 \mathrm{E}$ ), a Tipo $1 \mathrm{E}$ pode compor tanto a Tipo 1 como a Tipo E. Para a análise destas variáveis nas regressões, optou-se por deixar a Tipo 1E na Tipo 1, juntamente com a Tipo 1N. Portanto, para não haver duplicação, foi adicionada aos modelos apenas a Tipo 2E e não a Tipo E. Assim, com a inclusão das variáveis Tipo 1 e Tipo 2E, ficou de fora, servindo como base para os modelos de regressão, a variável $2 \mathrm{~N}$, que representa o financiamento de linhas de mercado em moeda nacional. Ou seja, as variáveis incluídas nas regressões (Tipo 1 e Tipo 2E) mostraram o diferencial de financiamento em relação aos financiamentos a partir de linhas de mercado em moeda nacional (Tipo 2N).

Em suma, foi possível identificar em notas explicativas a existência de 4 grupos de financiamento com características distintas, os quais, juntamente, totalizam $100 \%$ do passivo oneroso das empresas. No entanto, o estudo pretende explorar o efeito do acesso a fontes 
diferenciadas de financiamento na estrutura de capital de empresas brasileiras, portanto, foram utilizadas apenas as linhas Tipo $1(1 \mathrm{~N}+1 \mathrm{E})$ e Tipo 2E, as quais são assim consideradas por apresentarem taxas de juros diferenciadas em relação às linhas de mercado em moeda nacional (Tipo 2E). Exemplos de linhas do Tipo 1N são os recursos oriundos do BNDES; de linhas do Tipo 1E são os recursos oriundos do International Finance Corporation - IFC; de linhas do Tipo 2N são os financiamentos de Capital de Giro (indexador CDI); e de linhas do Tipo 2E são os Adiantamentos de Contratos de Câmbio - ACC, os Adiantamentos de Contratos de Exportação - ACE e os Pré-Pagamentos.

A inclusão das variáveis Tipo 1 e Tipo 2E trouxe resultados significativos (Tabela 5, Modelo com adição de Tipos) sem atrapalhar o modelo anterior, pois verifica-se que todos os resultados encontrados se mantiveram. Adicionalmente, estas variáveis contribuíram para aumentar o poder de explicação do modelo e apresentaram níveis de significância estatística (Tipo 1 a 1\% e Tipo 2E a 10\%) e econômica. Os coeficientes 0,095 e 0,06 das variáveis Tipo 1 e Tipo 2E, respectivamente, são significativos economicamente, demonstrando que o acesso a linhas diferenciadas de financiamento e a linhas em moeda estrangeira influenciou as decisões de financiamento de empresas brasileiras no período estudado, levando a não rejeição da hipótese da pesquisa.

Em trabalho recente, Bastos et al. (2009) analisaram os determinantes da estrutura de capital das companhias abertas na América Latina considerando fatores macroeconômicos e institucionais (crescimento do PIB, renda per capita, taxa anual de inflação, participação das companhias abertas na economia, carga fiscal e tempo médio para abertura de um negócio no país). Dentre os resultados mais expressivos, verificou-se que os principais determinantes da alavancagem foram: índice de liquidez corrente, rentabilidade do ativo - ROA, market to book value e tamanho. A variável crescimento do PIB foi a mais relevante em termos estatísticos dentre os fatores macroeconômicos e institucionais, apresentando relação negativa com o endividamento. Os autores afirmaram que este resultado corrobora a hipótese de que em tempos de crescimento econômico as empresas diminuem suas alavancagens por conta da maior disponibilidade de recursos internos, o que está de acordo com a teoria de pecking order, e ressaltam "que os fatores macroeconômicos e institucionais não podem mais ser desconsiderados, pois são fatores que ajudam a explicar o comportamento das empresas, embora ainda haja muito que se pesquisar nesse campo.” (BASTOS et al., 2009, p. 76).

\section{CONSIDERAÇÕES FINAIS}

Para estudar a estrutura de capital das empresas brasileiras acreditamos ser necessário, além de entender e aplicar o arcabouço teórico e as metodologias empíricas aplicadas às empresas dos países desenvolvidos, compreender as especificidades de nossa economia, de nossas instituições e de nossas empresas. Precisamos aprofundar no entendimento das nossas particularidades e de suas implicações para podermos avançar na compreensão de como as nossas empresas decidem sobre suas estruturas de capital.

Pretendemos neste trabalho ampliar a abordagem clássica de estudo dos determinantes do nível de endividamento das empresas a ponto de incorporar os elementos que julgamos ser particulares e importantes para a nossa realidade, com o intuito de responder a seguinte questão de pesquisa: em um ambiente de altas taxas de juros, o que fizeram as empresas brasileiras com 
suas estruturas de capital?

Similarmente ao que fizeram Faulkender e Petersen (2006), que incorporaram o "acesso aos mercados de bonds", incorporou-se neste trabalho o elemento "acesso a fontes diferenciadas (Tipo 1) e a linhas em moeda estrangeira (Tipo 2E)" no estudo dos determinantes dos níveis de endividamento de empresas brasileiras. A inclusão do acesso a fontes diferenciadas e a linhas em moeda estrangeira fundamenta-se na argumentação de autores que propõem a inclusão de variáveis que representem não apenas as características das empresas, mas também fatores institucionais e/ou de oferta de recursos.

Do nosso ponto de vista, a variável Tipo 1 faz bem o papel desta proxy, representando as particularidades de um país num período bastante especial da nossa história. Pode-se dizer que a variável Tipo 1 é a síntese do elemento institucional e de oferta de recursos no que diz respeito à solução que o país e suas instituições encontraram para contrapor o alto nível de taxas de juros. Se, por um lado, as condições do país pesavam, por outro, suas instituições abrandavam tal carga.

Em relação à variável Tipo 2E, o diferencial de taxas de juros, favorável às operações em moeda estrangeira, permitiu às empresas em vários momentos trabalharem a partir de uma base de taxas de juros diferente das taxas básicas domésticas. É impossível identificar claramente as empresas que aproveitaram e as que não aproveitaram estas oportunidades, mas a presença significativa de financiamentos em moeda estrangeira (Tabela 2, acima) é um forte indício de que, no geral, as empresas aproveitaram oportunidades, o que influenciou a estrutura de capital destas empresas.

Cabe enfatizar os resultados obtidos quando foram incorporadas as variáveis Tipos no modelo originalmente elaborado para explicar o endividamento total com apenas variáveis clássicas (Tabela 5, acima). A incorporação das variáveis Tipo1 e Tipo 2E trouxe contribuição importante visto que estas variáveis não atrapalharam o modelo e os resultados anteriores (com as variáveis clássicas) se mantiveram de forma robusta. Ainda, contribuíram para aumentar o poder de explicação do modelo e apresentaram níveis razoáveis de significância estatística (Tipo 1 a 1\% e Tipo 2E a 10\%) e econômica. Estes resultados levam a não rejeição da hipótese investigada na pesquisa: o acesso a fontes de recursos diferenciadas, como BNDES e Crédito Rural (as linhas Tipo 1), e recursos em moeda estrangeira (as linhas Tipo E), foi crucial para a determinação da estrutura de capital de empresas brasileiras no período 1997-2006. O acesso a estas fontes trouxe condições privilegiadas de captação e, por isso, produziu impactos nas decisões de financiamento das empresas, refletindo-se em seus níveis de endividamento.

Se voltarmos às perguntas "e nós, o que sabemos da estrutura de capital das nossas empresas? Como as nossas empresas escolhem suas estruturas de capital?", responderia a primeira com "ainda não muita coisa" e a segunda com "sabemos ainda muito pouco". Mas, de forma positiva, o presente trabalho e os seus resultados permitem-nos continuar acreditando que o caminho para aumentarmos a nossa compreensão é o entendimento das particularidades da nossa economia e das nossas instituições e o seu impacto no financiamento das empresas. 


\section{REFERÊNCIAS}

ALBANEZ, T.; VALLE, M. R. Impactos da assimetria de informação na estrutura de capital de empresas brasileiras abertas. Revista Contabilidade e Finanças, v. 20, n. 51, p. 6-27, 2009.

ASSAF NETO, A. Finanças corporativas e valor. 2. ed. São Paulo: Atlas, 2006.

ASSAF NETO, et al. Uma proposta metodológica para cálculo do custo de capital no Brasil. Revista de Administração da Universidade de São Paulo - RAUSP, v. 43, n.1, p. 72-83, jan./ mar. 2008.

BARCLAY, M. J.; SMITH JUNIOR, C. W. The maturity structure of corporate debt. The Journal of Finance, Chicago, v. 50, n. 2, p. 609-631, Jun. 1995.

BARCLAY, et al. The joint determination of leverage and maturity. Journal of Corporate Finance, Amsterdam, v. 9, p. 149-167, 2003.

BARNEA, A.; HAUGEN, R. A.; SENBET, L. W. A rationale for debt maturity structure and call provisions in the agency theoretic framework. The Journal of Finance, Chicago, v. 35, n. 5, p. 1223-1234, Dec. 1980.

BARNEA, A.; HAUGEN, R. A.; SENBET, L. W. Agency problems and financial contracting. New Jersey: Prentice-Hall Englewood Cliffs, 1985.

BASTOS, et al. Determinantes da estrutura de capital das companhias abertas na América Latina: um estudo empírico considerando fatores macroeconômicos e institucionais. Revista de Administração Mackenzie, v. 10, n. 6, 2009.

BOOTH, et al. Capital structure in developing countries. The Journal of Finance, Chicago, v. 56, n. 1, p. 87-130, Feb. 2001.

BREUSCH, T. S.; PAGAN, A. R. The lagrange multiplier test and its application to model specification in econometrics. Review of Economic Studies, v. 47, n. 1, p. 239-254, 1980.

DEMIRGÜÇ-KUNT, A.; MAKSIMOVIC, V. Institutions, financial markets, and firm debt maturity. Journal of Financial Economics, Amsterdam, v. 54, p. 295-336, 1999.

DIAMOND, D. W. Debt maturity structure and liquidity risk. The Quarterly Journal of Economics, Cambridge, v. 106, n. 3, p. 709-737, Aug. 1991.

FAULKENDER, M.; PETERSEN, M. A. Does the source of capital affect the capital structure? The Review of Financial Studies, New York, v. 19, n. 1, p. 45-79, 2006.

FÁVERO, et al. Análise de dados: modelagem multivariada para tomada de decisões. Rio de Janeiro: Elsevier, 2009.

GUEDES, J.; OPLER, T. The determinants of the maturity of corporate debt issues. The Journal of Finance, Chicago, v. 51, n. 5, p. 1809-1833, Dec. 1996. 
GUJARATI, D. N. Econometria básica. Rio de Janeiro: Elsevier, 2006.

HARRIS, M.; RAVIV, A. The theory of capital structure. The Journal of Finance, Chicago, v. 46, n. 1, p. 297-355, Mar. 1991.

JENSEN, M. C. Agency costs of free cash flow, corporate finance, and takeovers. The American Economic Review, Nashville, v. 76, n. 2, p. 323-329, May 1986.

KANE, et al. Debt policy and the rate of return premium to leverage. The Journal of Financial and Quantitative Analysis, Seattle, v. 20, n. 4, p. 479-499, Dec. 1985.

MEDEIROS, O. R.; DAHER, C. E. Testando teorias alternativas sobre a estrutura de capital nas empresas brasileiras. Revista de Administração Contemporânea, vol. 12, n. 1, p. 177-199, 2008 .

MINARDI, et al. Estimando o custo de capital de companhias fechadas no Brasil para uma melhor gestão estratégica de projetos. Insper Working Paper, 2007.

MODIGLIANI, F; MILLER, M. H. The cost of capital, corporation finance and the theory of investment. The American Economic Review, Nashville, v. 48, n. 3, p. 261-297, 1958.

MYERS, S. C. Determinants of corporate borrowing. Journal of Financial Economics, Amsterdam, v. 5, p. 147-175, 1977. Jul. 1984.

. The capital structure puzzle. The Journal of Finance, Chicago, v. 39, n. 3, p. 575-592,

. Capital structure. The Journal of Economic Perspectives, Nashville, v. 15, n. 2, p. 81-102, spring 2001.

.; MAJLUF, N. S. Corporate financing and investment decisions when firms have information that investors do not have. Journal of Financial Economics, Amsterdam, v. 13, p. 187-221, 1984.

NEWEY, W. K.; WEST, K. D. A simple, positive semi-definite, heteroskedasticity and autocorrelation consistent covariance matrix. Econometrica, New York, v. 55, n. 3, p. 703708, May 1987.

OZKAN, A. The determinants of corporate debt maturity: evidence from UK firms. Applied Financial Economics, Oxford, v. 12, n. 1, p. 19-24, 2002.

RAJAN, R.; ZINGALES, L. What do we know about optimal capital structure? Some evidence from international data. The Journal of Finance, Chicago, v. 50, n. 5, p. 1421-1460, Dec. 1995.

ROSS, et al. Administração financeira. Corporate finance. Tradução Antônio Zoratto Sanvicente. 2. ed. São Paulo: Atlas, 2002.

SMITH JUNIOR, C. W.; WARNER, J. B. Bankruptcy, secured debt, and optimal capital structure: comment. The Journal of Finance, Chicago, v. 34, n. 1, p. 247-251, Mar. 1979a. 
$\overline{7, \text { p. } 117} \overline{-161,1979 b .}$

. On financial contracting. Journal of Financial Economics, Amsterdam, v.

STOHS, M. H.; MAUER, D. C. Determinants of corporate debt maturity structure. The Journal of Business, Chicago, v. 69, n. 3, p. 279-312, Jul. 1996.

STREBULAEV, I. A. Do tests of capital structure theory mean what they say? The Journal of Finance, Chicago, v. 62, n. 4, p. 1747-1787, 2007.

TERRA, P. R. S. Estrutura de capital e os fatores macroeconômicos na América Latina. Revista de Administração da Universidade de São Paulo, São Paulo, v. 42, n. 2, p. 192-204, abr./ jun.2007.

TITMAN, S.; WESSELS, R. The determinants of capital structure choice. The Journal of Finance, Chicago, v. 43, n. 1, p. 1-19, Mar. 1988.

WOOLDRIDGE, J. M. Econometric analysis of cross section and panel data. Cambridge: MIT Press, 2002. 


\section{DADOS DOS AUTORES:}

\section{MAURÍCIO RIBEIRO DO VALLE}

Universidade de São Paulo, Faculdade de Economia, Administração e Contabilidade de Ribeirão Preto, Departamento de Contabilidade.

Av. dos Bandeirantes, 3900, Monte Alegre

14040-900- Ribeirão Preto, SP - Brasil

\section{TATIANA ALBANEZ}

Universidade de São Paulo, Faculdade de Economia, Administração e Contabilidade, Departamento de Contabilidade e Atuária.

Av. Prof. Luciano Gualberto, 908 FEA-3

Cidade Universitária

05508-900 - São Paulo, SP - Brasil 